\title{
In Situ Atomic Force Microscopy Observation of Octacalcium Phosphate (100) Face Dissolution in Weak Acidic Solutions
}

\author{
Kazuo Onuma ${ }^{1}$, Mayumi Iijima ${ }^{2}$ \\ ${ }^{1}$ National Institute of Advanced Industrial Science and Technology (AIST), Tsukuba, Japan \\ ${ }^{2}$ School of Dentistry, Asahi University, Mizuho, Japan \\ Email: ${ }^{*}$ k.onuma@aist.go.jp
}

Received 10 October 2014; revised 9 November 2014; accepted 9 December 2014

Copyright (C) 2015 by authors and Scientific Research Publishing Inc.

This work is licensed under the Creative Commons Attribution International License (CC BY). http://creativecommons.org/licenses/by/4.0/

(c) (i) Open Access

\begin{abstract}
Dissolution of the (100) face of octacalcium phosphate (OCP) single crystal in weak acidic solutions $\left(\mathrm{pH}=6.5 ; 25^{\circ} \mathrm{C}\right)$ was observed in situ using atomic force microscopy. Monomolecular steps (2.0 nm high) were observed; they originated from etch pits or crystal edges. Advancement of the dissolution process led to precipitation of nanoparticles as small as $\sim 10 \mathrm{~nm}$ even though the solution was undersaturated with respect to OCP. This precipitation of nanoparticles was accompanied by a drastic decrease in the dissolution rate; however, the substrate OCP continued to dissolve, indicating that dissolution and growth occurred simultaneously on the same surface. The precipitated nanoparticles coalesced and eventually covered the entire surface without changing the surface morphology of the substrate crystal. The step height after complete coverage was $\sim 2.0$ $\mathrm{nm}$, the same as that observed on the dissolving OCP surface. These findings indicate that the precipitated phase was a pseudomorph of OCP crystal.
\end{abstract}

\section{Keywords}

Octacalcium Phosphate, Dissolution, Atomic Force Microscopy, Pseudomorph

\section{Introduction}

Human tooth enamel is composed of rod-like carbonate-containing fluoridated hydroxyapatite micro-crystals [1] [2] and is the hardest tissue in the body. The crystals have high crystallinity elongated in the c-axis direction, and are parallel to each other [3]-[6]. In the early stage of enamel formation, the crystals are extremely thin rib-

\footnotetext{
*Corresponding author.
}

How to cite this paper: Onuma, K. and lijima, M. (2015) In Situ Atomic Force Microscopy Observation of Octacalcium Phosphate (100) Face Dissolution in Weak Acidic Solutions. Journal of Crystallization Process and Technology, 5, 1-8. 
bons that are dispersed in the enamel matrix [7]. These ribbons thicken during the maturation stage, and most organic components such as proteins exit the matrix [8]-[10], resulting in the formation of densely packed rodlike enamel crystals with a small amount of organic components remaining between them [11].

Intensive studies have been carried out to clarify the formation mechanism of tooth enamel; however, it still remains unclear. Several models of the enamel crystal formation have been proposed over the past 40 years [12]-[17]; the latest one is multi-step formation of enamel apatite from the amorphous phase with the aid of amelogenin molecules [18]-[21]. During the formation of tooth enamel, octacalcium phosphate $\left(\mathrm{Ca}_{8}\left(\mathrm{HPO}_{4}\right)_{2}\left(\mathrm{PO}_{4}\right) \cdot 5 \mathrm{H}_{2} \mathrm{O}\right.$; OCP $)$ is assumed to appear as the intermediate phase and to play a key role in enamel apatite formation [13]-[17]. This assumption is based on the fact that OCP structurally resembles hydroxyapatite $\left(\mathrm{Ca}_{10}\left(\mathrm{PO}_{4}\right)_{6}(\mathrm{OH})_{2} ; \mathrm{HAP}\right)$ and is its thermodynamically metastable phase. The OCP usually crystallizes as a thin blade or long ribbon in vitro and resembles the morphology of enamel crystals during their early stage.

Transmission electron microscopy observations have shown that HAP epitaxially grows on the OCP (100) face [14]-[16]. Therefore, the mechanism of transformation from OCP to HAP is the key to clarifying the enamel formation process. The details of this process thus need to be clarified. For example, it is unclear whether the OCP dissolves prior to HAP formation. This question is related to the cluster growth model of HAP. Previous investigations have shown that HAP grows with the calcium phosphate clusters as a growth unit under physiological solution conditions [22]-[25]. Since OCP contains the same cluster unit in its structure, direct structure-reconstruction to HAP is possible. Partial dissolution of OCP might occur, observable as the collapse of the crystal surface. Direct epitaxial growth of HAP without dissolution of OCP does not occur in this structure-reconstruction model.

If the OCP did not structurally resemble HAP, which seems inconsistent with the apatite-like layer in the OCP structure, HAP would simply grow after OCP dissolution due to their difference in solubility. In both HAP formation models, the key point is the dissolution of OCP; however, there have been no direct investigations of OCP dissolution. We have performed in situ observation of the dissolution of the OCP (100) face in weak acidic solutions at room temperature using atomic force microscopy (AFM).

\section{Experimental}

\subsection{Solution Preparation}

Simple $\mathrm{NaCl}$ solutions buffered using two different reagents were prepared in this investigation. One contained $50 \mathrm{mM} \mathrm{NaCl}$ buffered using $50 \mathrm{mM}$ 2-(N-morpholino)ethanesulfonic acid (MES)- $\mathrm{NaOH}$ at $\mathrm{pH} 6.5\left(25^{\circ} \mathrm{C}\right)$, and the other contained $50 \mathrm{mM} \mathrm{NaCl}$ buffered using $50 \mathrm{mM}$ sodium acetate-acetic acid at the same $\mathrm{pH}$ and temperature. Both solutions were filtering using $0.22-\mu \mathrm{m}$-pore syringe-type filters immediately before being used in AFM observations.

\subsection{AFM Observations}

AFM observations were done both in air (ex situ) and in solution (in situ). A Multimode-8 AFM (Bruker AXS Co.) was used for all observations.

A silicon single-crystal cantilever with a spring constant of $0.4 \mathrm{~N} / \mathrm{m}$ was used for the observations in air. The radius of the tip curvature of the cantilever was $\sim 2 \mathrm{~nm}$. High-speed tapping mode (4 Hz scan rate and 512 scan lines) was used.

A silicon-nitride cantilever with a spring constant of $0.8 \mathrm{~N} / \mathrm{m}$ was used for the observations in solution. The radius of the tip curvature of the cantilever was $\sim 2 \mathrm{~nm}$. The sample crystal was set in an O-ring-sealed glass cell. It was connected to a solution reservoir (syringe with $5 \mathrm{~mL}$ volume), and the solution was refreshed every $1.5 \mathrm{~h}$ after observation started. Peak-force tapping mode (2 Hz scan rate and 384 scan lines) was used. When the dissolution rate was very low in the late stage of reaction, the number of scan lines was increased to 512. Images of the reaction process were continuously captured; the recording time per image was $\sim 2.5 \mathrm{~min}$ in the case of 384 scan lines. The image gain and peak-force set point control parameters were manually set and then adjusted as needed during the observation.

\subsection{OCP Single-Crystal Synthesis}

Supersaturated calcium phosphate solutions were prepared by mixing appropriate volumes of $10 \mathrm{mM}$ $\mathrm{Ca}\left(\mathrm{CH}_{3} \mathrm{COO}\right)_{2} \cdot \mathrm{H}_{2} \mathrm{O}$ and $40 \mathrm{mM} \mathrm{NaH} \mathrm{PO}_{4} \cdot 2 \mathrm{H}_{2} \mathrm{O}$ stock solutions with a sufficient amount of ultra pure water to 
achieve a final volume of $400 \mathrm{~mL}$, a Ca/P molar ratio of 1.33, and the final Ca and $\mathrm{PO}_{4}$ concentrations of 2.22 $2.50 \mathrm{mM}$ and $1.67-1.88 \mathrm{mM}$, respectively. The reaction vessel was sealed and placed in a thermostated incubator $\left(60^{\circ} \mathrm{C}\right)$ without stirring for $15-23 \mathrm{~h}$. OCP crystals grew both on the solution-air interface and on the bottom of the vessel. Clouding of the solution due to continuous nucleation in the solution was not observed irrespective of the initial solution concentration. The solution $\mathrm{pH}$ decreased with the growth of OCP crystals, and the final solution $\mathrm{pH}$ was between 5.73 and 6.01 .

After the reaction was completed, the solution was quickly removed by using a suction pump and a cellulose-acetate membrane filter with a pore size of $0.2 \mu \mathrm{m}$ (ADVANTEC). Residual solutions around the OCP crystals were absorbed using soft paper, and the crystals were immediately rinsed using suction pump filtration and a mixed alcohol solution (99.5\% ethanol and 99.5\% 2-isopropanol at a volume ratio of 1:1). The rinsing was performed three times, and then the crystals were dried in an incubator at $37^{\circ} \mathrm{C}$. The dried crystals were wrapped in charta and kept in a dry incubator (humidity less than $30 \%$ ). All reagents used were reagent grade, and ultra pure water (BIOPACK ${ }^{\circledR}$, Q-POD, specific resistance of $18.2 \mathrm{M} \Omega$, TOC of $2 \mathrm{ppb}$ ) was used throughout the experiments.

\subsection{Crystal Characterization}

The synthesized crystals were characterized using an X-ray diffractometer (XRD) (Rint 2500, Rigaku; monochromated $\mathrm{CuK} \alpha, 200 \mathrm{~mA}, 50 \mathrm{kV}$ ).

\section{Results and Discussion}

\subsection{Grown Crystals and Their XRD Patterns}

Figure 1(a) shows a transmission optical microscopy image of a synthesized crystal. The crystals typically had an elongated thin plate with a curved tip, like that of a Japanese sword. Many tiny crystals co-precipitated on the surface irrespective of the initial solution concentration. This co-precipitation always occurred when the size of the grown crystals exceeded $\sim 0.3 \mathrm{~mm}$. While the crystallographic orientations of the tiny crystals varied, they tended to take the same orientation as that of the substrate crystal as they increased in size.

Figure 1(b) shows an XRD pattern of grown crystals. The characteristic 100 peak of OCP at $2 \theta=4.7^{\circ}$ was sharp and intense [26]. Neither the peak at $2 \theta=10.8^{\circ}$ for HAP, nor that at $2 \theta=11.0^{\circ}$ for dicalcium phosphate dehydrate, was observed, indicating that the synthesized crystals were only OCP (see expanded inset). Thin-film XRD measurements (data not shown) showed that the well-developed face of crystals corresponded to (100).

There was little remarkable peak at around $2 \theta=10^{\circ}-20^{\circ}$, where many small peaks normally appear for ordinary single-crystal OCP. This suggests that the crystallographic symmetry of the grown crystals might have been higher than that of ordinary OCP crystals, although the morphology of the growth hillock observed on the (100) face did not show the regular morphology corresponding to a highly symmetrical crystal, as described below. This means that any change in the structural symmetry was very small even if it actually occurred.

Figure 1(c) shows another XRD pattern for crystals grown in this investigation. Note that the small sub-peak at $2 \theta=4.4^{\circ}$ was closed to the most intense 100 peak (see expanded inset); this has not been previously reported for XRD patterns of OCP crystals. The position of this sub-peak depended on the growth condition, and sometimes there were several such sub-peaks. Whether there is systematic correlation between the growth conditions and the appearance of sub-peaks has not yet been clarified.

The appearance of sub-peaks could be related to the structure of the $\mathrm{HPO}_{4}-\mathrm{OH}$ layer in the OCP. A recent investigation showed that the XRD pattern of OCP lacked the 100 peak when the $\mathrm{HPO}_{4}-\mathrm{OH}$ layer disappeared in the OCP structure [27]. While this pseudo-OCP consisted of stacked apatite-like layers, the XRD pattern did not show a peak at $2 \theta=10.8^{\circ}$, which corresponds to HAP. Raman and Fourier-transformed infrared spectroscopies also did not show any sign of HAP. If the $\mathrm{HPO}_{4}-\mathrm{OH}$ layer was expanded or shrunk by some means, the subpeaks around the 100 main peak might appear because the 100 peak is strongly related to the physical property of the $\mathrm{HPO}_{4}$-OH layer. Our XRD data suggest that the OCP structure is flexible and could take several metastable forms corresponding to slight differences in the growth conditions.

\subsection{Synthesized OCP Surface Morphology}

Figure 2(a) shows an AFM image of a grown OCP (100) face. The XRD pattern of the crystal showed a small 

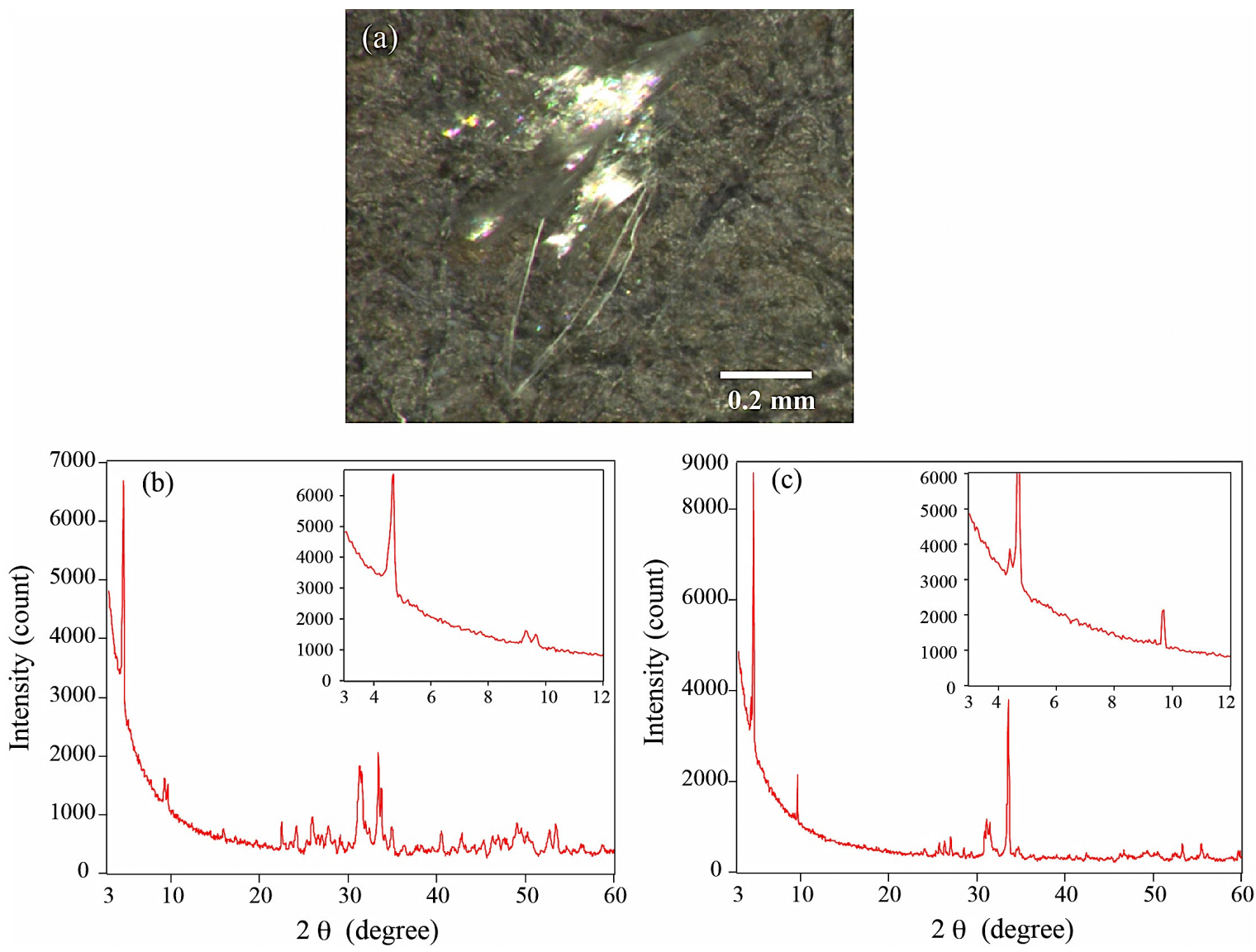

Figure 1. (a) Synthesized OCP single crystal; (100) face was well developed; (b) Powder XRD pattern of OCP crystals. Most intense peak (at $2 \theta=4.7^{\circ}$ ) corresponds to 100 diffraction. Inset shows expanded XRD pattern at low $2 \theta$ values; (c) Powder XRD pattern of OCP crystals showing pattern different from that of ordinary OCP. Small sub-peak appeared at $2 \theta=$ $4.4^{\circ}$. Expanded XRD pattern in inset clearly shows this sub-peak.
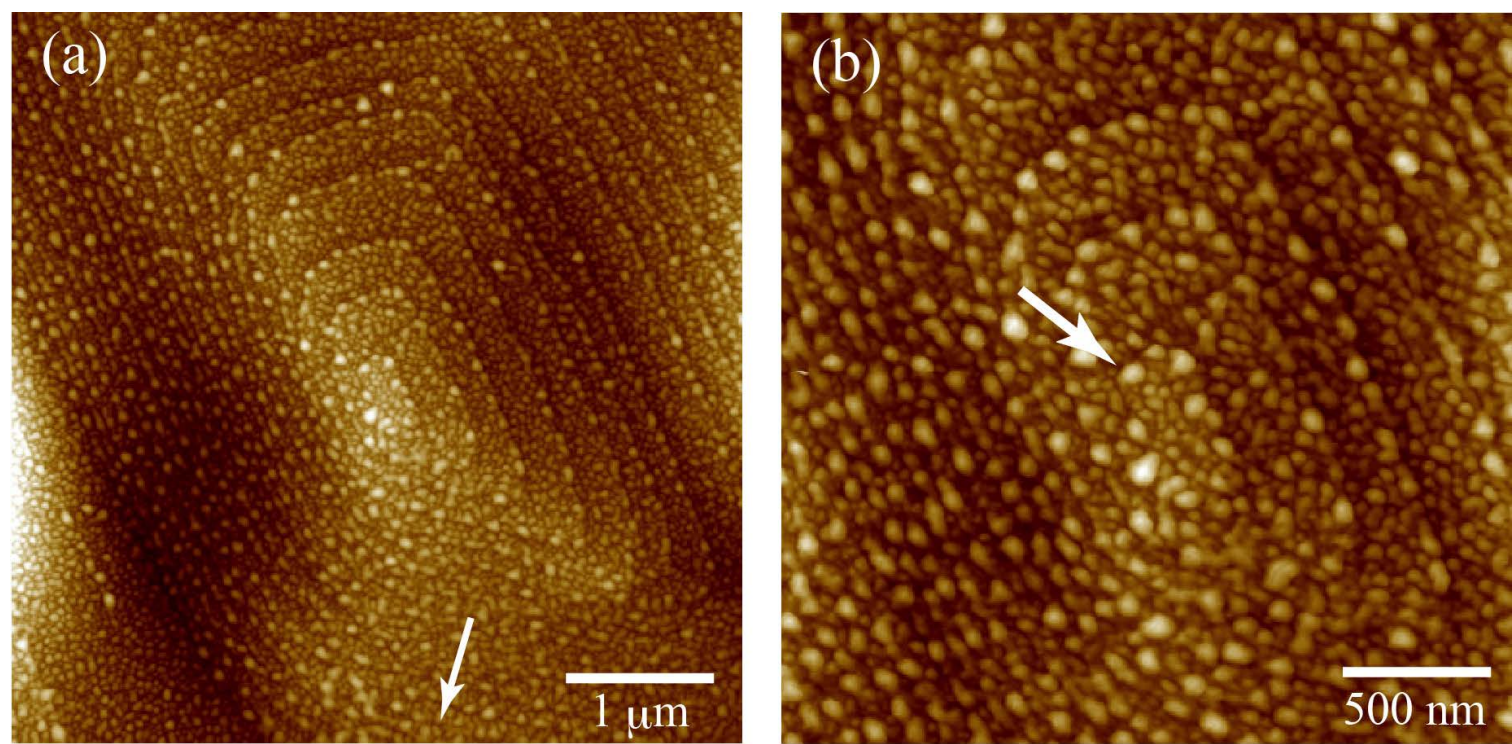

Figure 2. (a) AFM image of OCP (100) face observed in air. Asymmetric rectangular growth hillock, especially in direction of arrow, was observed. Surface was covered with particles of various sizes; (b) Enlarged image of (a). Growth hillock was constructed of spiral steps. Arrow shows spiral center. 
sub-peak close to the 100 peak. The surface was covered with small particles of various sizes. These particles were observed on the surface even though the alcohol rinsing was quickly performed. Their appearance was not due to the use of alcohol because rinsing with pure water had the same result. Their size, number, and shape differed between growth experiments. In some cases, their size exceeded $200 \mathrm{~nm}$, and they had irregular shapes, resembling those of droplets. When the crystals were kept at low humidity $(30 \%-35 \%)$ in air, they were stable on the order of months. However, at higher humidity, the particles disappeared and the surface became macroscopically flat (although rough in nanometer scale) within a day. The origin of these particles was probably submicroliter aliquots remaining on the surface when the crystals were removed from the mother solution. The residual drops on the surface immediately reacted with the substrate crystal and solidified.

As shown in Figure 2(a), a growth hillock was clearly observed on the surface. It had an asymmetrical shape, especially for the orientation indicated by the arrow. The inter-step distances on the right side were wide while those on the left side were narrow, indicating asymmetric bond-strength depending on the orientation.

The enlarged image in Figure 2(b) clearly shows that the growth hillock was constructed of spiral steps. The arrow indicates the spiral center corresponding to screw- or mixed-type dislocation ends. The spiral direction was clock-wise. The growth mechanism of OCP crystal has not yet been clarified, and the kind of growth (two-dimensional nucleation or spiral) that occurs on the surface has not been determined. Our observations have shown that spiral growth at least occurs on the (100) face. Although the height of each step was difficult to determine accurately due to the precipitated particles, the average height was $\sim 2.0-2.5 \mathrm{~nm}$.

\subsection{OCP (100) Face Dissolution}

Figure 3 shows a series of in situ AFM images of (100) face dissolution. The XRD pattern of the crystal corresponded to that of ordinary OCP without sub-peaks, such as shown in Figure 1(c). The dissolution behavior of OCP showing sub-peaks in the XRD pattern, however, was qualitatively the same as that of this ordinary OCP without sub-peaks.

We found that the dissolution behaviors for the two $\mathrm{NaCl}$ solutions with different buffers were qualitatively the same. Therefore, only the results for the solution buffered using MES are described here.

When the solution was injected into the cell, the particles observed on the original surface immediately disappeared and step trains due to dissolution developed on the surface (Figure 3(a)). Figure 3(a) (and Figures 3(c)-(h)) was obtained by applying second-order flattening to the entire image and first-order line-by-line planefit for both the $\mathrm{x}$ - and y-directions to the raw image. This was done to make it easier to see the images. The image in Figure 3(b) is of the same position as that in Figure 3(a), but first-order flattening and xy plane-fit were applied to show the height difference. The section profile along the line A-B (inset in lower part of image) shows that the minimal dissolution step height was $2.00 \pm 0.07 \mathrm{~nm}$. This is slightly larger than that expected from the unit cell parameters and the OCP symmetry, $1.86 \mathrm{~nm}$. This suggests that the unit cell parameters and symmetry of the synthesized OCP differed slightly from those previously reported for OCP [26].

The duration from solution injection to starting observation was less than $30 \mathrm{~s}$; however, almost all the particles on the surface observed in air dissolved. The observed steps (see Figure 3(a)) moved quickly, which made it impossible to maintain the step image between two continuous scanned frames. As shown in Figure 3(c) (after $2.5 \mathrm{~min}$ ), the step morphology (inclination of each step in y-direction) differed from that shown in Figure 3(a). This was due to the time needed to complete the scanning of each image. Since $\sim 2.5$ min was needed to obtain one image, advancement of a step near the upper part of the observed area differed from that of one near the lower part due to the high step velocity, as shown by a comparison of the two parts with those in the previous image.

At 2.5 minutes after starting observation, small particles $\sim 10 \mathrm{~nm}$ in diameter and $\sim 3 \mathrm{~nm}$ in height suddenly appeared on the surface, as seen in Figure 3(c). The duration until the first observation of precipitated particles depended on the crystals. In many cases, it occurred within $15 \mathrm{~min}$, but in some cases $\sim 1 \mathrm{~h}$ was necessary.

These particles were not dust particles in the solution because their number quickly increased over time (Figure 3(d)). The precipitation of materials clearly occurred although the bulk solution was undersaturated $(-100 \%)$ with respect to the calcium phosphates. When the precipitation started, the velocity of the original steps drastically decreased. The inclination of each step shown in Figure 3(d) in the y-direction was almost the same as that for the ones shown in Figure 3(a), indicating that the scan rate was high enough to maintain the step morphology between two continuous scanned frames. However, the OCP surface continued to dissolve despite the precipitation. The morphology of the step front (shown by the arrows in Figure 3(d)) became irregular, par- 

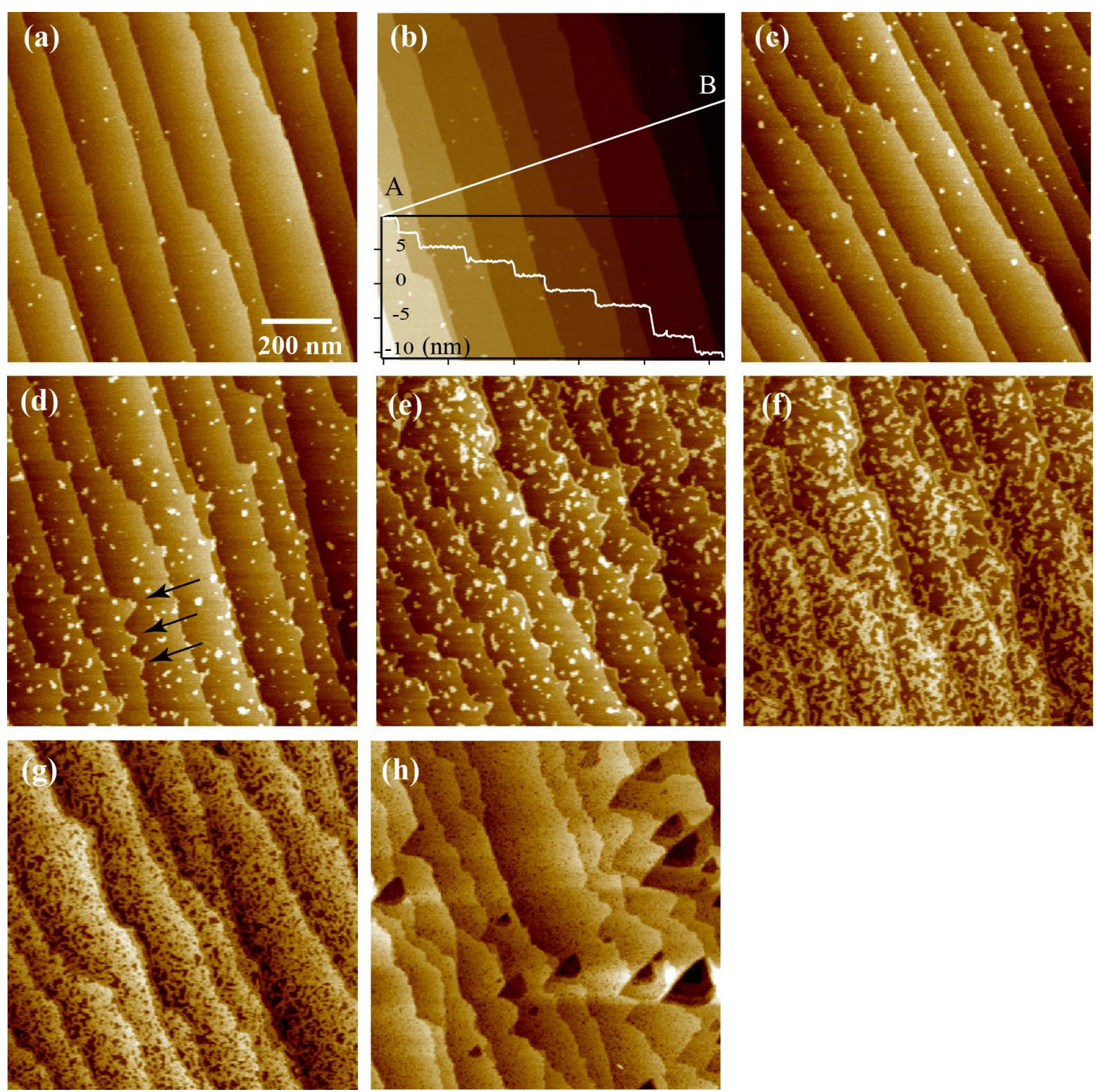

Figure 3. In situ AFM imagaes of OCP (100) face dissolving in weak acidic solution. (a) Dissolution steps observed immediately after starting observation (0 min); (b) Same area as shown in (a) after applying first-order flattening to raw image. Section profile along A-B line shows that minimal height of dissolution steps was $2.00 \pm 0.07 \mathrm{~nm}$; (c) Image after 2.5 min. Small particles $(\sim 10 \mathrm{~nm})$ started to precipitate on surface although solution was undersaturated with respect to OCP; (d) Image after 5 min. Number of particles increased, but substrate OCP continued dissolving, as shown by irregular morphology of step front (arrows); (e) Precipitated particles started to coalesce (7.5 min); (f) Coalesced particles created marble pattern on surface (10 min); (g) OCP surface was fully covered with coalesced particles (18 min); covereing layer was porous; (h) Surface after $2 \mathrm{~h}$. Note that surface pattern was essentially the same as that of original OCP. Minimal step height was $\sim 2.0$ $\mathrm{nm}$, the same as that observed in (a).

ticularly when the dissolution was slow. Figure 3(d) revealed that the precipitated materials were not OCP because, if the materials had been OCP, the surface would have turned to growth and each step would have moved in the opposite direction due to particle incorporation. These results clearly show that the dissolution of substrate OCP and the growth of a phase other than OCP simultaneously occurred on the same surface.

At 7.5 min after starting observation (see Figure 3(e)), the precipitated particles started to coalesce, and their behavior resembled that of droplets. At 10 min (Figure 3(f)), the surface showed a marble pattern due to particle coalescence, and it was fully covered by precipitated material at 18 min (Figure 3(g)). The covering material 
was porous; it is seen as many tiny black dots in the image. The process from first precipitation of particles to coverage of the entire surface due to coalescence completed very quickly, 20 min. This time was independent of the incubation time until the first precipitation of particles.

After the coverage of entire OCP surface, pores in the precipitated phase gradually became buried over time (on the order of hours). Figure 3(h) shows the image captured at $2 \mathrm{~h}$ after starting observation. The minimal step height in Figure 3(h) was 2.0 nm, the same as that for the image shown in Figure 3(b), and the surface morphology after coverage was essentially similar to that of the original dissolved OCP surface. These results indicate that the precipitated phase was a pseudomorph of OCP.

The precipitation of particles probably occurred due to a local increase in the calcium phosphate concentration at the interface due to OCP dissolution. This means that the precipitated particles had lower solubility than OCP ones. Among the calcium phosphates that appear at room temperature under a neutral $\mathrm{pH}$ condition, only HAP holds true in this situation. Of particular interest is that each particle took an irregular form when it coalesced with other particles (see Figure 3(e) and Figure 3(f)), suggesting that the particles were amorphous-like material. Amorphous calcium phosphate, of course, does not correspond to this material because its solubility is much higher than that of OCP. Therefore, the precipitated particles were probably amorphous HAP, which has not been previously found. A detailed characterization of this unknown phase will be reported in a forthcoming article.

After coverage by this unknown phase, the surface again started to dissolve, but the dissolution rate was much lower than that of the OCP in the initial reaction stage (before particle precipitation). Although quantitative analysis of the dissolution rate has not been performed, the rate for the unknown phase was assumed to be less than $1 / 5$ for OCP. This is consistent with the unknown phase having lower solubility than OCP.

\section{Conclusion}

Dissolution of synthesized OCP single crystal (100) face was first observed using in situ AFM. Our investigation has revealed important information about the phase transformation from OCP to HAP. That is, there may be a transformation mechanism that differs from those of two conventional models of transformation, i.e., epitaxial growth of HAP on OCP and direct structure-reconstruction between OCP and HAP. This new mechanism is the intermediate-phase (amorphous HAP?) based pseudomorphic transformation. A peritectic reaction would likely occur between OCP and this new intermediate phase after pseudomorph formation, and entire crystal likely changes to HAP when the solution is supersaturated with respect to HAP. Clarification of this new mechanism would greatly contribute to understanding the formation mechanism of human tooth enamel.

\section{References}

[1] Aoba, T. and Moreno, E.C. (1990) Changes in the Nature and Composition of Enamel Mineral during Porcine Amelogenesis. Calcified Tissue International, 47, 356-364. http://dx.doi.org/10.1007/BF02555887

[2] Aoba, T. and Moreno, E.C. (1992) Changes in the Solubility of Enamel Mineral at Various Stages of Porcine Amelogenesis. Calcified Tissue International, 50, 266-272. http://dx.doi.org/10.1007/BF00296292

[3] Watson, M.L. (1960) The Extracellular Nature of Enamel in the Rat. Journal of Biophysical and Biochemical Cytology, 23, 447-497.

[4] Rönnholm, E. (1962) The Amelogenesis of Human Teeth as Revealed by Elcectron Microscopy. (II) The Development of the Enamel Crystallites. Journal of Ultrastructure Research, 6, 249-303. http://dx.doi.org/10.1016/S0022-5320(62)80036-7

[5] Nylsen, M.U., Eanes, E.D. and Omnell, K.A. (1963) Crystal Growth in Rat Ename. Journal of Cell Biology, 18, 109123. http://dx.doi.org/10.1083/jcb.18.1.109

[6] Travis, D.F. and Glimcher, M.J. (1964) The Structure and Organization of, and the Relationship between the Organic Matrix and the Inorganic Crystals of Embryoic Bovine Enamel. Journal of Cell Biology, 23, 447-497. http://dx.doi.org/10.1083/jcb.23.3.447

[7] Diekwisch, T.G.H., Berman, B.J., Gentner, S. and Slavkin, H.C. (1995) Initial Enamelcrystals Are Not Spatially Associated with Mineralized Dentin. Cell and Tissue Research, 279, 149-167. http://dx.doi.org/10.1007/BF00300701

[8] Kerebel, B., Daculsi, G. and Kerebel, L.M. (1979) Ultrastructural Studies of Enamel Crystallites. Journal of Dental Research, 58, 844-850. http://dx.doi.org/10.1177/00220345790580023701

[9] Weiss, M.P., Vogel, J.C. and Frank, R.M. (1981) Enamel Crystallites Growth: Width and Thickness Study Related to 
the Possible Presence of Octacalcium Phosphate during Amelogenesis. Journal of Ultrastructure Research, 76, 286292. http://dx.doi.org/10.1016/S0022-5320(81)80059-7

[10] Robinson, C., Briggs, H.D., Atkinson, P.J. and Weatherell, J.A. (1984) Matrix and Mineral Changes in Developing Enamel. Journal of Dental Research, 58, 871-880. http://dx.doi.org/10.1177/00220345790580024101

[11] Weidmann, S.M., Weatherell, J.A. and Hamm, S. (1967) Variations of Enamel Density in Sections of Human Teeth. Archives of Oral Biology, 12, 85-97. http://dx.doi.org/10.1016/0003-9969(67)90145-8

[12] Fearnhead, R.W. (1960) Mineralization of Rat Enamel. Nature, 188, 509-600. http://dx.doi.org/10.1038/188509a0

[13] Brown, W.E. (1966) Crystal Growth of Bone Mineral. Clinical Orthopaedics, 44, 205-220.

[14] Nelson, D.G.A. and Barry, J.C. (1989) High Resolution Electron Microscopy of Nonstichrometric Apatite Crystals. The Anatomical Record, 224, 265-276. http://dx.doi.org/10.1002/ar.1092240217

[15] Iijima, M., Tohda, H., Suzuki, H., Yanagisawa, T. and Moriwaki, Y. (1992) Effect of $\mathrm{F}^{-}$on Apatite Octacalcium Phosphate Intergrowth and Morphology in a Model System of Tooth Enamel Formation. Calcified Tissue International, 50, 357-361. http://dx.doi.org/10.1007/BF00301634

[16] Miake, Y., Shimoda, S., Fukae, M. and Aoba, M. (1993) Epitaxial Overgrowth of Apatite Crystals on the Thin-Ribbon Precursor at Early Stages of Porcine Enamel Mineralization. Calcified Tissue International, 53, 249-256. http://dx.doi.org/10.1007/BF01320910

[17] Iijima, M. and Moradian-Oldak, J. (2004) Control of Octacalcium Phosphate and Apatite Growth by Amelogenin Matrices. Journal of Materials Chemistry, 14, 2189-2199. http://dx.doi.org/10.1039/b401961j

[18] Beniash, E., Simmer, J.P. and Margoris, H.C. (2005) The Effect of Recombinant Mouse Amelogeneses in the Formation and Organization of Hydroxyapatite Crystals in Vitro. Journal of Structural Biology, 149, 182-190. http://dx.doi.org/10.1016/j.jsb.2004.11.001

[19] Tao, J., Pan, H., Zeng, Y., Xu, X. and Tang, R. (2007) Roles of Amorphous Calcium Phosphate and Biological Additives in the Assembly of Hydroxyapatite Nanoparticles. Journal of Physical Chemistry B, 111, 13410-13418. http://dx.doi.org/10.1021/jp0732918

[20] Wang, L., Guan, X., Chang, D., Moradian-Oldak, J. and Nancollas, G.H. (2007) Amelogenin Promotes the Formation of Elongated Apatite Microstructures in a Controlled Crystallization System. Journal of Physical Chemistry C, 111, 6398-6404. http://dx.doi.org/10.1021/jp0675429

[21] Yang, X.L., Wang, L., Qin, Y., Sun, Z., Henneman, Z.J., Moradian-Ordak, J. and Nancollas, G.H. (2010) How Amelogenin Orchestrates the Organization of Hierarchical Elongated Microstructures of Apatite. Journal of Physical Chemistry B, 114, 22293-22300. http://dx.doi.org/10.1021/jp910219s

[22] Onuma, K. and Ito, A. (1998) Cluster Growth Model for Hydroxyapatite. Chemistry of Materials, 10, 3346-3351. http://dx.doi.org/10.1021/cm980062c

[23] Onuma, K., Kanzaki, N., Ito, A. and Tateishi, T. (1998) Growth Kinetics of Hydroxyapatite (0001) Face Revealed by Phase Shift Interferometry and Atomic Force Microscopy. Journal of Physical Chemistry B, 102, 7833-7838. http://dx.doi.org/10.1021/jp981617u

[24] Treboux, G., Layrolle, P., Kanzaki, N., Onuma, K. and Ito, A. (2000) Symmetry of Posner’s Cluster. Journal of the American Chemical Society, 122, 8323-8324. http://dx.doi.org/10.1021/ja994286n

[25] Kanzaki, N., Treboux, G., Onuma, K., Tsutsumi, S. and Ito, A. (2001) Calcium Phosphate Clusters. Biomaterials, 22, 2921-2929. http://dx.doi.org/10.1016/S0142-9612(01)00039-4

[26] Elliot, J.C. (1994) Structure and Chemistry of the Apatites and Other Calcium Orthophosphates. Elsevier, Amsterdam.

[27] Sugiura, Y., Onuma, K., Nagao, M. and Yamazaki, A. (2014) Alteration of Formation Dynamics and Material Structure in Phase Transformation from Amorphous Calcium Phosphate to Octacalcium Phosphate Using Immobilized Carboxylic-Functional Group on Gold Nanoparticles. American Mineralogist, Submitted. 
Scientific Research Publishing (SCIRP) is one of the largest Open Access journal publishers. It is currently publishing more than 200 open access, online, peer-reviewed journals covering a wide range of academic disciplines. SCIRP serves the worldwide academic communities and contributes to the progress and application of science with its publication.

Other selected journals from SCIRP are listed as below. Submit your manuscript to us via either submit@scirp.org or Online Submission Portal.
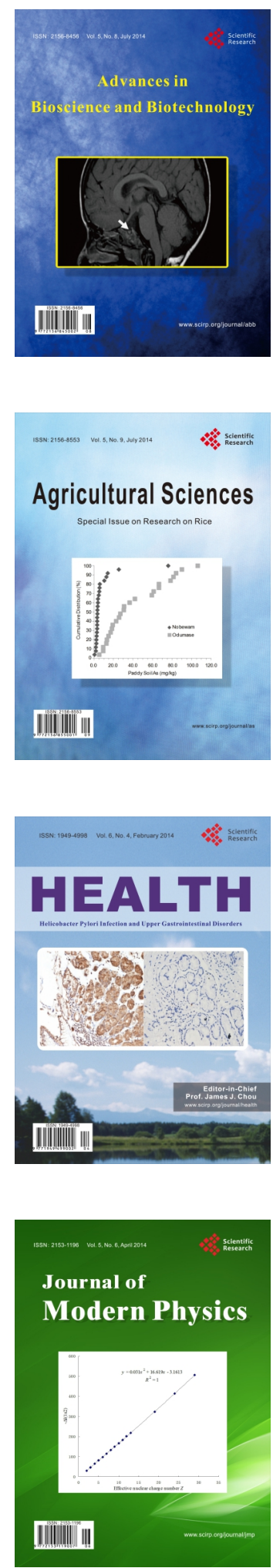
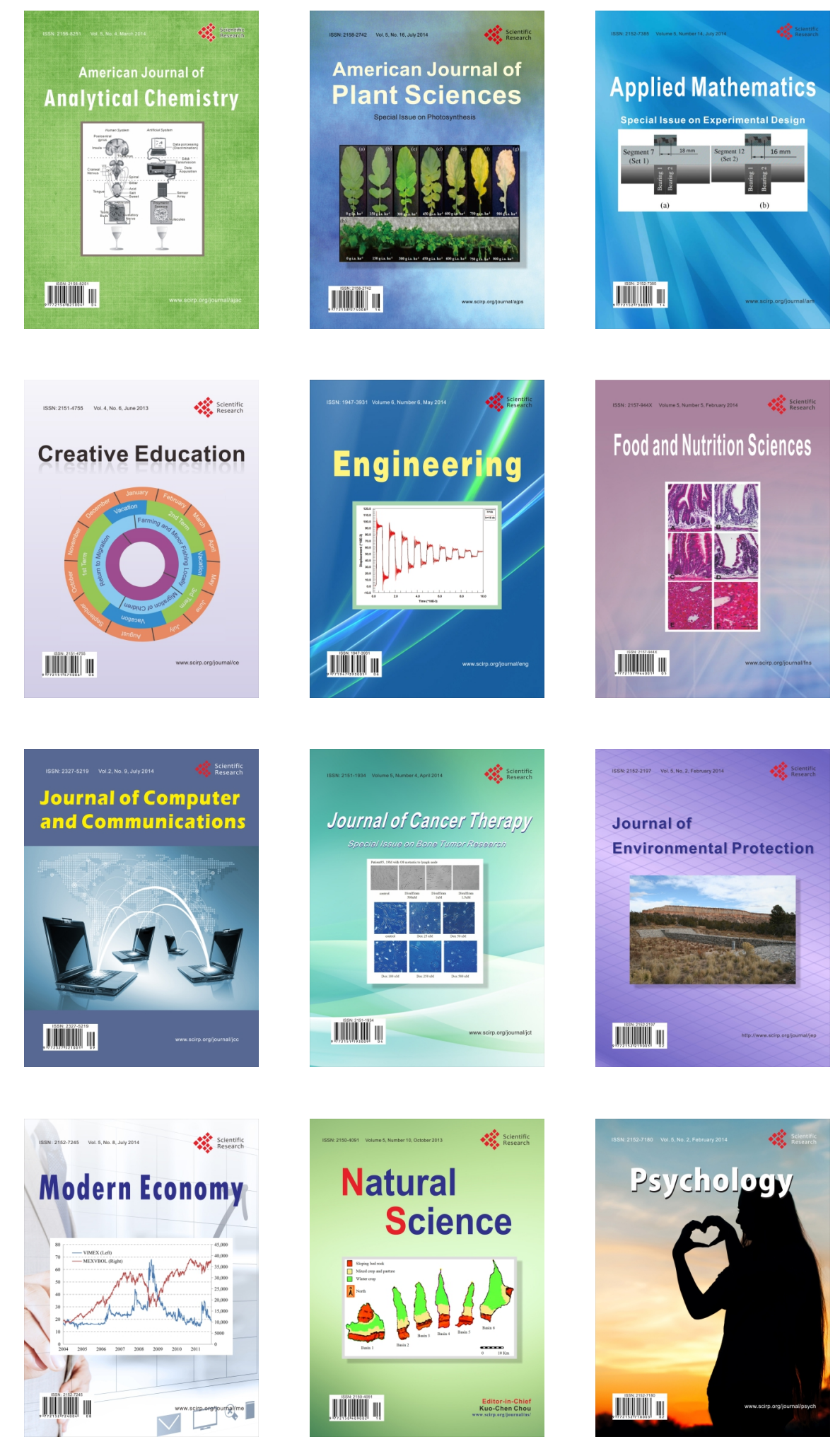